\title{
FGDP(UK) and PHE publish revised guidance on radiation protection
}

The Faculty of General Dental Practice (FGDP $[\mathrm{UK}]$ ) and Public Health England (PHE) have published revised guidance on radiation protection in dental practice.

The second edition of Guidance Notes for Dental Practitioners on the Safe use of X-ray Equipment sets standards of good practice for the safe use of X-ray equipment in dental practice, and is endorsed by the College of General Dentistry (CGDent).

Presenting definitive, detailed and comprehensive recommendations in a logically ordered and intelligible format, Guidance Notes for Dental Practitioners on

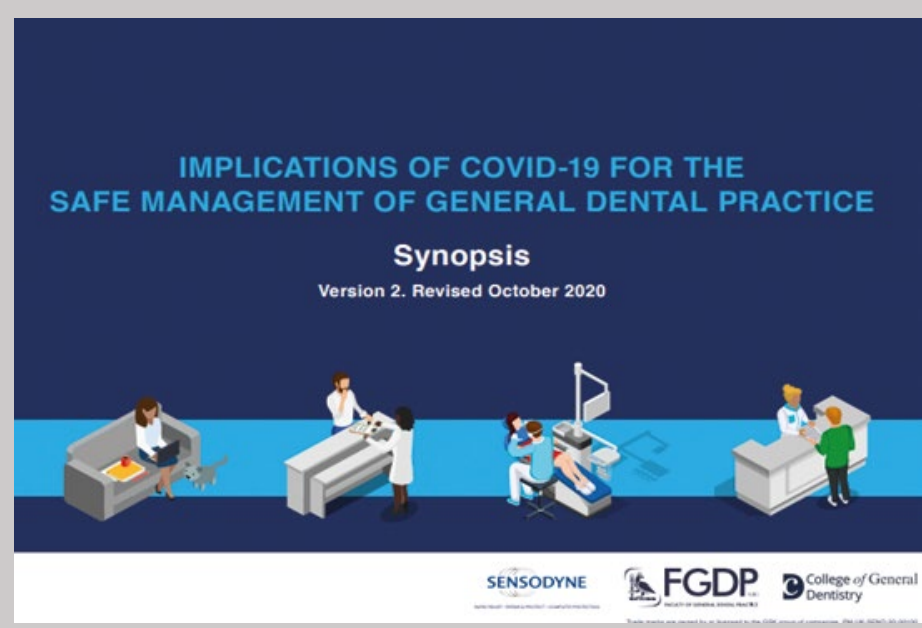

the Safe use of X-ray Equipment, $2^{\text {nd }}$ Edition is designed as a reference for the whole primary care dental team.

The guidance covers both administrative and practical matters, taking into account developments in dental X-ray equipment, imaging technology and legislation since the first edition, which was published in 2001 by the National Radiological Protection Board (now part of PHE's Centre for Radiation, Chemical and Environmental Hazards).

Ian Mills, Dean of FGDP(UK) and Trustee of the College of General Dentistry, said: 'The core function of the FGDP is

to raise the

standards of care delivered to patients through education of the dental profession and the provision of evidencebased guidance, and we have been delighted to work with Public Health England to publish a

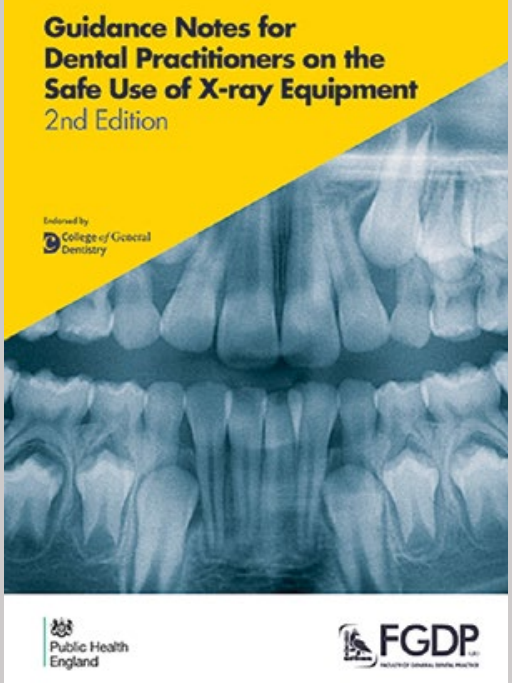

second edition of the Guidance Notes for Dental Practitioners on the Safe Use of X-ray Equipment. For almost two decades, this has been an important text in setting standards for the safe use of X-ray equipment in dental practices, and this updated edition will undoubtedly continue to be a key reference document for the whole primary care dental team.'

The guidance is freely available on the FGDP website.

\section{Inequalities will widen without clear commitment from Scottish Government}

As new data reveal the oral health gap shows little signs of closing, the British Dental Association Scotland has warned that decades of progress on children's dental health risks going into reverse as COVID19 pushes unacceptable inequalities to new levels.

The latest report of the National Dental Inspection Programme shows that Primary 1 children from the most deprived communities experience more than four times the level of tooth decay compared to their counterparts in the least deprived areas (1.78 versus 0.40 decayed, missing or filled teeth per child).

In school year 2019/20, 74\% of Primary 1 children were free from tooth decay - that's up 3 percentage points (from $71 \%$ ) from the last report in 2018 and up 28 percentage points (from $45 \%$ ) since the programme started in $2002 / 03$. These figures also show that the average number of decayed, missing or filled teeth per child reduced from 2.76 in 2002/03 to 1.04 in 2019/20.

But the BDA has warned that stark and persistent inequalities will widen as a result of the pandemic, given the collapse in access to routine services, the suspension of public health programmes and the impact of sugarrich lockdown diets.

The pioneering Childsmile programme has been paused since Scotland first entered lockdown in March. The Childsmile Executive group has been working on a remobilisation plan but timings will depend on levels of COVID-19 in the community.

While NHS practices will be permitted to perform a full range of treatment from 1 November, practices will be operating at a fraction of their former capacity. It is anticipated the reintroduction of the preCOVID-19 funding model for dentistry will decimate NHS practices, in light of ongoing restrictions, higher costs and reduced patient numbers. GPs in Scotland are still being funded to pre-pandemic level.

Robert Donald, Chair of the British Dental Association's Scottish Council, said: 'COVID-19 risks undoing decades of progress in improving the dental health of our children.

'Dentistry in Scotland is at a turning point. Routine check-ups remain off the cards for most families, our public health programmes are struggling, and high street practices face a deeply uncertain future.

'The oral health gap between rich and poor - which has proved so stubborn - will widen unless we see real commitment from the Scottish Government.' 